\title{
Correspondence
}

\section{Research in spirituality and mental health}

We are aware that the methodology, interpretation and evaluation of research on spirituality and mental health are complex matters which are not without their controversies and difficulties. The measurement of spirituality (which is to be contrasted with religiosity in this regard) is necessarily subjective, and easily prone to confounding with psychological variables. Alongside healthy forms of spirituality there are pathological forms of spirituality, and harmful forms of religion and religious practice, which are clearly detrimental to mental well-being. Not surprisingly, therefore, there are negative as well as positive associations in the research literature charting the relationships between spirituality, religiosity and mental health. For this reason we did not suggest in our article ${ }^{2}$ that 'research unequivocally shows an association between religiosity and well-being' ${ }^{3}$ but rather stated that 'research demonstrates largely positive associations between religiosity and well-being'. Our cited reference in support of this contention was the Handbook of Religion and Health, a volume written by Harold Koenig and his colleagues, which reviewed 1200 studies that were critiqued according to methodology and outcome. ${ }^{4}$ We might also have quoted Koenig's more recent review in the Canadian Journal of Psychiatry, ${ }^{5}$ which reaches a similar evidence-based conclusion that, although there are undoubtedly unhealthy forms of religious and spiritual involvement, the usual associations are with better coping and healthier functioning.

The editorial by Dan Blazer in the same issue of the Canadian Journal of Psychiatry, ${ }^{6}$ cited by Hansen \& Maguire, ${ }^{3}$ does not suggest that there is an unequivocal association between religiosity and well-being. Nor does it claim that 'The research findings are wildly contradictory and it would be unreasonable to draw any firm conclusion on the basis of current knowledge'. ${ }^{3}$ Rather, Blazer summarises Koenig's review as showing that 'studies to date generally support a positive association between (religion and (or) spirituality) and mental health'. However, Blazer does importantly acknowledge that this association is 'a tough topic to research'. One of the reasons he gives for this is that it is difficult to be objective on matters about which we hold very deep beliefs. Blazer goes on to warn that 'Neglect of the religious dimension, not to mention refusal to discuss religious matters with our patients, may seriously cut off meaningful communication and significantly undermine the therapeutic relationship'. He concludes that 'even though the task is tough, neglect is even more difficult to justify'.

Clinicians, researchers and patients do hold very deep beliefs on these matters. It is for this reason that it is important not to rely only on impressions derived from clinical experience but also to refer to evidence-based research and reviews. If we cannot eliminate bias in our interpretation of these findings, we can at least minimise it.

1 Crowley N, Jenkinson G. Pathological spirituality. In Spirituality and Psychiatry (eds CHC Cook, A Powell, A Sims): 254-72. RCPsych Publications, 2009.
2 Dein S, Cook CHC, Powell A, Eagger S. Religion, spirituality and mental health. Psychiatrist 2010; 34: 63-4.

3 Hansen LK, Maguire N. Divine intervention in mental health. Psychiatrist 2010; 34: 258-9.

4 Koenig HG. Handbook of Religion and Mental Health. Academic Press, 1998.

5 Koenig HG. Research on religion, spirituality, and mental health: a review. Can J Psychiatry 2009; 54: 283-91.

6 Blazer DG. Religion, spirituality, and mental health: what we know and why this is a tough topic to research. Can J Psychiatry 2009; 54: 281-2.

Christopher C. H. Cook, Chair, Spirituality and Psychiatry Special Interest Group, Royal College of Psychiatrists, Consultant Psychiatrist, Tees, Esk and Wear Valleys NHS Foundation Trust, Professorial Research Fellow, Department of Theology and Religion, Durham University, email: c.c.h.cook@durham.ac.uk; Simon Dein, Secretary, Spirituality and Psychiatry Special Interest Group, Royal College of Psychiatrists, Consultant Psychiatrist, Princess Alexandra Hospital, Senior Lecturer, University College London; Andrew Powell, Former Consultant Psychotherapist and Honorary Senior Lecturer, Oxfordshire Mental Healthcare Trust and University of Oxford; Sarah Eagger, Consultant Psychiatrist, Central and North West London NHS Foundation Trust, Honorary Clinical Senior Lecturer, Imperial College London, Co-Chair of the National Spirituality and Mental Health Forum.

doi: 10.1192/pb.34.7.304

\section{No religion or spirituality and mental health}

Many articles have been written about the importance of recognising patients' spiritual and religious beliefs and trying to understand them so that patients might be better engaged with services and that there might be a better therapeutic relationship. However, little has been written concerning agnostic or atheist views of patients. Surely this is of equal importance?

It is easy for those professionals who have religious beliefs to say a person's faith can be a source of coping - but how do they approach a person who has no beliefs? Do they try to convert them or claim to have enough faith for the two of them?

Can those professionals with strong beliefs or faith truly understand those with none? How do they align their own beliefs to ensure proper engagement and a satisfactory therapeutic relationship? The matter definitely needs further research and discussion.

Clive Mackin is a psychiatric nurse, email: pb@rcpsych.ac.uk doi: $10.1192 / p b .34 .7 .304 a$

\section{Declare, declare!}

To me, the authors' response ${ }^{1}$ to Peter Bruggen's letter ${ }^{2}$ reflects a lack of understanding of the issue of bias in regard to declarations of interest. Surely, the most important reason for declarations of interest is to allow editors and readers to judge whether bias might have crept into a publication. Although the influence of the pharmaceutical industry, through financial relationships with clinicians or academics, is undoubtedly a source of bias, it is not the only source of bias that should be 
declared. Why should a cognitive-behavioural therapy-trained researcher or anyone with a particular leaning not declare that interest? It is not complicated to state succinctly that there is a potential bias. It is simple to do and aids transparency. Let the readers decide! The authors' distinction between 'conflicts of interest' and 'perspectives of interest' is splitting hairs and appears pedantic and defensive. Declare, declare!

\section{Declaration of interest}

Peter Bruggen and I worked together in 1990 and have been good friends since then. I subscribe to www. healthyskepticism.org.

1 Cook CHC, Dein S, Powell A, Eagger S. Declarations of interest. Psychiatrist 2010; 34: 259.

2 Bruggen P. Declarations of interest. Psychiatrist 2010; 34: 259.

Morris Zwi is Child and Adolescent Psychiatrist, Cochrane Collaboration author and editor, email: morris.zwi@swlstg-tr.nhs.uk

doi: $10.1192 / p b .34 .7 .304 b$

\section{Meaning-centred approaches: what about psychodynamics?}

In Wallang's tour de force ${ }^{1}$ (history of Western philosophy in four pages) arguing for a narrative-based approach to psychiatric consultation, there was a striking omission: nowhere was psychodynamic/psychoanalytic psychiatry mentioned. Yet this etiolation of psychodynamics underpins the aridity of diagnosis-focused psychiatry that he bemoans.

Psychodynamic approaches enlarge semiotic space in two main ways. ${ }^{2}$ First, they bring into the field all the communications - verbal and non-verbal, conscious and unconscious - that arise between patient and professional, not merely stated symptoms. Wallang himself illustrates this via his 'noticing' his patient's diagnostically 'irrelevant' Taoist bedside reading; this brought into focus a different, non-pathological dimension of the patient's life. Second, they offer a set of developmental meanings which help understand how it is that this individual finds herself or himself in this particular dilemma at this particular juncture in her or his life. Wallang's 'personal meanings' are invariably illuminated by this developmental perspective. His last-ditch drug-addicted patient who found solace in the thought that there is 'motion in inertia' might be referring to a childhood experience of a depressed 'inert' mother, his own 'motions' (pleas for attention?, 'shitty' feelings?) towards her, and the later discovery of drugs as a short cut to assuagement of longing.

Was Wallang's lacuna tactical (don't frighten the horses) or technical (psychodynamics still not fully evidence-based)? Either way, despite this conspicuous absence, his piece was a welcome change from standard psychiatric journal fare.

Jeremy Holmes is Visiting Professor, School of Psychology, University of Exeter, UK, email: j.a.holmes@btinternet.com

1 Wallang P. Wittgenstein's legacy and narrative networks: incorporating a meaning-centred approach to patient consultation. Psychiatrist 2010; 34: 157-61.

2 Holmes J. Exploring in Security: Towards an Attachment-Informed Psychoanalytic Psychotherapy. Routledge, 2009.
Author's reply I would like to address some of the points raised by Professor Jeremy Holmes in his letter.

He asks whether my omission of the psychodynamic approach was 'tactical' or 'technical'. It is the case that psychodynamic psychotherapy has been unable to demonstrate any convincing evidence supporting the explanatory basis of the psychodynamic approach. This does not necessarily mean that evidence cannot be found. It is a problem experienced in all science to differing degrees, ${ }^{1}$ the question being: how do we derive scientific knowledge, how do we know that what we know is right?

These evidential problems are bound up with another question raised by Professor Holmes, namely the general validity of all 'meaning' statements. The history of psychiatry reveals the evolution of the meaning-centred approach. Porter $\&$ Berrios $^{2}$ detail its development: the confinement of reason during the Enlightenment, through the liberation of the 'hysterical' patient with Freud as 'interpreter'. An extrapolation of these developments ultimately presages the next phase of evolution: a reappraisal of what an acceptable interpretation of the 'patient voice' should be. Inevitably, there will always be a degree of interpretation; the question is how much interpretation is plausible without supporting evidence? The narrative method adopts a stance which attempts to liberate the patient perspective by laying down the fetters of possibly invalid interpretations which up until now have been lacking in evidence and may ultimately remain so unless we can design a process which demonstrates their validity as explanatory statements. Ultimately, the level of evidence demanded is dictated by the claims of a theory. The narrative approach is an adjunct to facilitate communication; it makes no claims to diagnostic or explanatory validity, unlike psychoanalysis or psychodynamics. The explanatory statements within psychodynamics are often stretched beyond the limits of plausibility in a search for meaning without any adequate supporting evidence. Narrative aims to liberate the patient's own voice from overly speculative interpretations, it promotes patient equality and transparency, valuing what helps the patient in their suffering.

My argument was not to be divisive or champion the pre-eminence of any one modality over another, be that biological, social or psychological. The jostling for authority between these camps is well known and in my opinion fruitless. My main aim in writing the article was to highlight the current dilemma we face as clinicians in trying to understand patient meaning, and argue (I hope) for a discussion about the integration of all strands of current learning leading to a comprehensive, multidimensional, meaning-centred approach. This would better reflect the complex aetiology of mental illness and surely help to create a humane working method which would promote a deeper understanding of our patients. It would also lead to the realisation that our patients are equal participants and allow us to move into the next phase of psychiatry, the overdue liberation of the patient's own voice, freeing them from any single interpretive or explanatory authority and allowing further recognition and hopefully alleviation of their suffering. The narrative approach is well equipped to facilitate this transition. 